\title{
A Review Related to Midwifery Led Model of Care
}

\author{
Shahnaz Shahid ${ }^{\star}$, Rafat Jan, Rahat Najam Qureshi and Salma Rattani
}

Aga Khan University School of Nursing and Midwifery, Karachi, Pakistan

*Corresponding author: Shahnaz Shahid, Senior Instructor \& Midwifery Coordinator, Aga Khan University School of Nursing and Midwifery, Karachi, Pakistan, Tel: 02134935470; E-mail: Shahnaz.shahid@aku.edu

Received date: Aug 25, 2014; Accepted date: Sept 26, 2014; Published date: Oct 18, 2014

Copyright: $\odot 2014$ Shahid S, et al. This is an open-access article distributed under the terms of the Creative Commons Attribution License, which permits unrestricted use, distribution, and reproduction in any medium, provided the original author and source are credited.

\begin{abstract}
Background: Midwifery led care (MLC) is a model of care in which perinatal care is provided to women throughout different phases of childbirth by a midwife.

Objective: This paper aims to provide a literature review on MLC.

Methods: A variety of databases and reports were considered to do the literature review on MLC. The search was limited from 1991 to 2011 by using keywords. A total of 50 articles were critically appraised for this review.

Findings: The main theme that emerged was women's satisfaction with MLC. Satisfaction was integrated with midwife's presence throughout childbirth, experience to enhance normality in childbirth, cost-effectiveness of MLC, and facilitation of women's choice and control during labor.

Conclusion: The review concludes that MLC is women-friendly as it considers and respects women's needs holistically during childbirth.
\end{abstract}

Keywords: Midwifery led care; Midwife; Childbirth and women's experiences

\section{Overview}

This article provides a brief literature review on MLC from women's experiences, and it discusses women satisfaction with MLC as the main theme assimilated with midwife's presence during childbirth to enhance normality, and respecting women's needs, and efficiently providing safe and competent care.

\section{Process of Literature Search}

For this review, a literature search was done through various online databases including: Google Scholar, Cochrane Database of Systematic Reviews, Pub med, and Science Direct. Relevant literature included research articles and published reports were reviewed. Published studies from peer reviewed and indexed journals were also selected. The following key words were used for the search: midwifery-led care/ MLC, midwifery-led units/ MLU, experiences of mothers/ women about MLC during the antepartum, intrapartum, and postpartum periods/ childbirth/ perinatal period.

By limiting the literature search from 1991 to 2011, the keywords were entered and a total of 236 articles were found. Initially, all the articles titles were scanned; and a total of 128 articles were found relevant to the topic under discussion. Then, abstracts and reference list of the selected articles were read. Finally, only 50 articles were included in the review, and those were critically appraised and analyzed. The relevant articles were published in the following journals: British Journal of Obstetrics and Gynaecology, Bio Med Central Pregnancy and Childbirth, Journal of Perinatal Education, Midwifery, Journal of Midwifery and Women's Health, Birth, Archives of Gynaecology and Obstetrics, Journal of Quality Safe Health Care, Journal of Obstetrics, Gynaecology, and Reproductive Medicine, RCM Midwives Journal, Journal of Nursing Inquiry, and Journal of Advance Nursing.

Some of the relevant reports were also reviewed such as Report from the Royal College of Obstetrics and Gynaecology, Report from the MidU study, Cochrane Review, Winterton Report, the World Health Organization Report, Report of the Department of Health, Report of the International Confederation of Midwives, and Report of the Australian College of Midwives.

\section{Introduction}

For every woman, childbirth is described as a unique comprehensive experience and most women can have a safe vaginal delivery. The philosophy of MLC focuses on client satisfaction and believes on the natural ability of women to deliver the baby [1]. As supported by studies, MLC is a woman and family-centred process that enhances client satisfaction by focusing on the holistic and humanistic principles of health maintenance and promotion of women [2-6].

MLC is acknowledged as the most suitable and cost effective care provided in the normal childbirth process. This model also includes assessment of risks and recognition of complications during the childbirth process, so that early interventions could be provided and appropriate referral could be planned for better management of the cases. Use of medical interventions such as administration of analgesia and episiotomy is minimized. In MLC, the midwife plays a fundamental role in coordinating care for women and linking with other health care professionals as required (ICM Position Statement, 2011). 
The benefits to women and their newborns during childbirth in MLC are: having spontaneous vaginal birth, a feeling of being in control during labor, and early initiation of breast feeding. In addition, women have continuity of care provision, most of the time by a known midwife, focusing on the physical, psychological, spiritual, and social factors [1].

\section{Women's satisfaction}

Evidences from the literature shows that client satisfaction is the main aim of MLC. Satisfaction occurs when the desired needs are achieved [7]. To achieve client satisfaction, literature about the perceptions and experiences of women revealed that satisfaction with continuity of care, satisfaction of women with midwives' competencies, satisfaction with cost in MLC, satisfaction of having choice and control during labor, and satisfaction with the presence of a midwife, all contribute to the childbirth experience of women [8].

Studies suggest that women are more satisfied in MLC because they feel that they are better prepared for parenthood as they get better support from the midwife. Moreover, women believe that MLC promotes client's teaching, counseling, advocacy, and collaboration with the midwife for consultation or referral during the child birth cycle. In addition, family planning services are provided to women, abnormal conditions in the mothers and newborns are detected, and emergency interventions are provided in the absence of medical help (International Confederation of Midwives, 2002). Furthermore, women feel increased satisfaction because in MLC, hospitalization of a woman during the antenatal period is reduced [9] and women have less chances of suffering from postnatal depression [10].

A study conducted by Biro, Waldenstrom, Brown and Pannifex [10] compared team midwifery care during the antenatal, intranatal, and postnatal periods with standard (shared model) maternity care. Low and high risk women $(\mathrm{n}=1000)$ were randomly assigned in team midwifery and standard care. Women's views were assessed four months after the birth of the baby by using a postal questionnaire. Results showed that the team midwifery care was associated with increased satisfaction during antenatal, intranatal, and some aspects of postnatal care.

Another study by Waldenstrom, Rudman, and Hildingsson [11], aimed to investigate women satisfaction with intrapartum and postpartum care and the risk of not being satisfied, in relation to a woman's socio-demographic background, physical and emotional well-being in early pregnancy, labor outcomes, care in organization, and women's subjective assessment of aspects of care. Study participants $(n=2686)$ were Swedish speaking women booked for antenatal care during 3 weeks from 1999-2000 who completed questionnaires in early pregnancy and 2 months in to the postpartum period. The results of the study revealed that $10 \%$ of the women were not satisfied with intrapartum care due to lack of support by midwife, lack of support from partner, little involvement in decision making during labor, and dissatisfaction with the birthing environment. Among all the participants, $26 \%$ of the women were not satisfied with postpartum care due to insufficient time and support provided by the midwife for breastfeeding.

\section{Women experience with continuity of care}

Continuity of care is one of the important expectations of women related to MLC. Continuity of care means a woman is able to develop a relationship with a midwife to work in partnership for the provision of her care during the antenatal, intranatal, and the postnatal periods (ICM, 2005). The Australian College of Midwives [12] Australian College of Midwives emphasizes that it is the right of every pregnant lady to have access to continuity of care by a known midwife for her different phases of childbirth, because it has many health benefits and satisfaction for the woman, her newborn, and her family. Women feel that continuity of care by midwives contributes to quality care provision in MLC [13]; in other words, the continuity of midwifery care is associated with increased satisfaction [10].

A study was conducted by Waldenstrom, McLachlan, Forster, Brennecke, and Brown [14] to evaluate the effect of a team midwife care program on satisfaction during different phases of childbirth at the Royal Women's Hospital in Melbourne, Australia. Women were randomly allocated, at the time of booking in early pregnancy, to team midwife care $(n=495)$ or standard care $(n=505)$. Satisfaction was measured by a questionnaire retrospectively two months after the birth of the baby. It was found that team midwifery care was associated with increased satisfaction; the differences between the groups were most noticeable for antenatal care, less noticeable for intrapartum care, and least noticeable for postpartum care. Thus, the data suggested that client satisfaction with intrapartum care was related to the continuity of the caregiver.

A qualitative study was done in Sweden to describe women's opinions about what is important to them during pregnancy and birth. This study was based on the responses of 827 pregnant women to an open question that was completed in the second trimester. By using content analysis, the statements were clustered into four major themes: 1) desirable characteristics of midwife, 2) care during antenatal period, 3) care during intranatal period, and 4) care during postnatal period. The study concluded that patient-centred individualized approach with child bearing mothers and their partners would increase client's satisfaction [6].

Studies suggest that compared to standard (shared) maternity care, continuity of midwifery care reduces the need for medical intervention, offers autonomy to women during the antenatal, intranatal, and postnatal periods, and promotes better infant outcomes. These studies have also revealed that women who received MLC were more likely to be attended by a known midwife during the childbirth phases; hence, continuity of care was enhanced $[1,3,5,7,15-19]$ A few studies state that to enhance continuity of care for women during child birth, it is important to work together in a therapeutic alliance with the primary health-care providers, from the initial phases of childbirth [3,19].

\section{Midwife 'being with women'}

The "being with" of a midwife is highly appreciated by women during childbirth because it leads to the development of the midwifewoman relationship', which affects women's experiences related to childbirth [19]. As a result of this relationship, women feel physically and psychologically safe and well supported by the presence of the midwife [20,21]. Furthermore, as emphasized by [22], this relationship provides the basis to the midwife for organizing and planning care according to women's needs to enhance their satisfaction. Moreover, midwives utilize their own physical and emotional energy to encourage, support, and comfort women during childbirth to have a positive child birth experience [23].

James [24], in her doctoral dissertation, explored the concept of 'midwife-woman relationship' among midwives and women. The 
Page 3 of 7

findings concluded that midwives were with women throughout the childbirth period and they provided physical and emotional care to women. Moreover, the findings revealed 'midwife's being with women' during the entire intranatal period [19].

Apart from the satisfaction of women with the presence of a midwife during childbirth, in terms of client's satisfaction, literature also supports the presence of companion during labor. Describing the importance of companion during the birthing process, studies have suggested that the presence of birth partners (husband) and/or midwifery support workers (doula) can result in a positive birth experience and lead to increased patient satisfaction [1,5,7] (Table 1).

\begin{tabular}{|c|c|c|c|}
\hline Study Title & Author & Year & Findings \\
\hline $\begin{array}{l}\text { Women's Evaluations of Maternity Care, The } \\
\text { MidU Survey [5] }\end{array}$ & Begley, Devane and Clarke & 2009 & $\begin{array}{l}\text { Midwifery-led care is as safe as consultant-led care, and it } \\
\text { results in less intervention, leads to greater satisfaction in } \\
\text { some aspects of care and is cost-effective. }\end{array}$ \\
\hline $\begin{array}{l}\text { Satisfaction with Team Midwifery Care for Low- } \\
\text { and High-Risk Women: A Randomized } \\
\text { Controlled Trial [10] }\end{array}$ & Biro,Ulla, Brown and Pannifex & 2003 & $\begin{array}{l}\text { Increased women's satisfaction with maternity care } \\
\text { compared with standard care. }\end{array}$ \\
\hline $\begin{array}{l}\text { Views of Chinese women and health } \\
\text { professionals about midwife-led care in China } \\
\text { [3] }\end{array}$ & $\begin{array}{l}\text { Cheung, Mander, Wang ,Fu, Zhou and } \\
\text { Zhang }\end{array}$ & 2010 & $\begin{array}{l}\text { Midwifery led model of care is good for its association with } \\
\text { increased satisfaction in a context of extraordinarily high } \\
\text { caesarean rates. }\end{array}$ \\
\hline $\begin{array}{l}\text { Assessment of social psychological } \\
\text { determinants of satisfaction with childbirth in a } \\
\text { cross-national perspective [9] }\end{array}$ & Christiaens and Bracke & 2007 & $\begin{array}{l}\text { Women with high self- efficacy showed more satisfaction } \\
\text { with self. }\end{array}$ \\
\hline $\begin{array}{l}\text { Childbirth experience questionnaire }(C E Q) \text { : } \\
\text { development and evaluation of a } \\
\text { multidimensional instrument [8] }\end{array}$ & Dencker,Taft, Bergqvist, Lilja and Berg & 2010 & $\begin{array}{l}\text { Women were satisfied with continuity of care provided by } \\
\text { midwives and her continuous presence, cost of care in } \\
\text { MLC, choice and control provided during labor. }\end{array}$ \\
\hline $\begin{array}{l}\text { Continuing Education Module Midwifery Care: } \\
\text { Reflections of Midwifery Clients [4] }\end{array}$ & Doherty & 2010 & MLC is women and family centered \\
\hline $\begin{array}{l}\text { Births in two different delivery units in the same } \\
\text { clinic-A prospective study of healthy } \\
\text { primiparous women }[25,26]\end{array}$ & Eide, Nilsen and Rasmussen & 2009 & $\begin{array}{l}\text { Midwife-led units promote normal births and enhance } \\
\text { women satisfaction by minimizing the use of medical } \\
\text { interventions }\end{array}$ \\
\hline Factors related to childbirth satisfaction [27] & Goodman, Mackey and Tavakoli & 2004 & $\begin{array}{l}\text { During childbirth personal control of the woman was a } \\
\text { crucial factor that was related to the women's satisfaction } \\
\text { with the childbirth experience. }\end{array}$ \\
\hline $\begin{array}{l}\text { Women's expectations and experiences of } \\
\text { childbirth [7]. }\end{array}$ & Gibbins and Thomson & 2001 & $\begin{array}{l}\text { The positive attitudes of the midwives i.e. caring for } \\
\text { women during pregnancy and labor, information given } \\
\text { during pregnancy and labor and encourage women to } \\
\text { make decisions during labor. }\end{array}$ \\
\hline $\begin{array}{l}\text { Midwife-led versus other models of care for } \\
\text { childbearing women [1] }\end{array}$ & $\begin{array}{l}\text { Hatem, Sandall, Devane, Soltani and } \\
\text { Gates }\end{array}$ & 2008 & $\begin{array}{l}\text { MLC believes on the natural ability of women to have } \\
\text { childbirth and it focuses on client satisfaction. }\end{array}$ \\
\hline $\begin{array}{l}\text { Women's Perspectives on Maternity Services in } \\
\text { Sweden: Processes, Problems, and Solutions }\end{array}$ & Hildingsson and Thomas. & 2007 & $\begin{array}{l}\text { Patient-centered approach with mothers and their partners } \\
\text { increase clients' satisfaction. }\end{array}$ \\
\hline $\begin{array}{l}\text { The rhetoric of informed choice: perspectives } \\
\text { from midwives on intrapartum fetal heart rate } \\
\text { monitoring }\end{array}$ & Hindley and Thomson & 2005 & $\begin{array}{l}\text { Informed choice and the power of the midwife were not } \\
\text { reportedly translated into practice. }\end{array}$ \\
\hline Continuous support for women during childbirth & Hodnett, Gates, Hofmeyr and Sakala, & 2007 & $\begin{array}{l}\text { In MLC continuity of care by midwife to child bearing } \\
\text { women was enhanced. }\end{array}$ \\
\hline $\begin{array}{l}\text { Outcomes Associated with Planned Home and } \\
\text { Planned Hospital Births in Low-Risk Women } \\
\text { Attended by Midwives in Ontario, Canada, } \\
\text { 2003-2006: A Retrospective Cohort Study [28] }\end{array}$ & Hutton, Reitsma and Kaufman & 2009 & In MLC continuous care is provided to woman during labor. \\
\hline $\begin{array}{l}\text { Continuity of carrer: what does it mean and } \\
\text { Does it matter to midwives and birthing } \\
\text { Women? }\end{array}$ & McCourt, Stevens, & 2005 & Women appreciated continuity of care provider. \\
\hline $\begin{array}{l}\text { An exploratory metasynthesis of midwifery } \\
\text { practice in the United States [29] }\end{array}$ & Kennedy, Rousseau and Low & 2003 & $\begin{array}{l}\text { Identified the midwife as an 'instrument' of care; the woman } \\
\text { as a 'partner' in care; an 'alliance' between the woman and } \\
\text { midwife was present in the 'environment' of care. }\end{array}$ \\
\hline
\end{tabular}


Page 4 of 7

\begin{tabular}{|c|c|c|c|}
\hline $\begin{array}{l}\text { Woman centered care'? An exploration of } \\
\text { professional care in midwifery practice }\end{array}$ & Kirkham & 2004 & $\begin{array}{l}\text { Choice during childbirth is discussed in terms of place of } \\
\text { delivery and use of medical interventions in the obstetric } \\
\text { led model of care. }\end{array}$ \\
\hline $\begin{array}{l}\text { Women's experiences of labour and birth: an } \\
\text { evolutionary concept analysis [30] }\end{array}$ & Larkin, Begley and Devane & 2009 & $\begin{array}{l}\text { Identification of the core attributes of the labor and birth } \\
\text { experience may provide a framework for future } \\
\text { consideration and investigation including further analysis of } \\
\text { related concepts such as 'support' and 'control'. }\end{array}$ \\
\hline $\begin{array}{l}\text { Core and Developing Role of the Midwife } \\
\text { Midwifery }\end{array}$ & Masterson & 2010 & In MLC use of medical interventions is reduced. \\
\hline $\begin{array}{l}\text { Midwifery-led birthing units. Obstetrics, } \\
\text { Gynecology and Reproductive Medicine }\end{array}$ & Mohajer, Hughes and Ghosh & 2009 & $\begin{array}{l}\text { In MLC women attended by a known midwife during the } \\
\text { childbirth enhanced continuity of care. }\end{array}$ \\
\hline $\begin{array}{l}\text { Creating a 'safe' place for birth: An empirically } \\
\text { grounded theory. New Zealand College of } \\
\text { Midwives Journal }\end{array}$ & Parratt and Fahy & 2004 & $\begin{array}{l}\text { Due to midwife's presence, women feel safe and well } \\
\text { assisted by the midwife. }\end{array}$ \\
\hline $\begin{array}{l}\text { Choice" and place of delivery: a qualitative } \\
\text { study of women in remote and rural Scotland }\end{array}$ & $\begin{array}{l}\text { Pitchforth, Teijlingen, Watson, Tucker, } \\
\text { Kiger Ireland, Farmer Rennie, Gibb } \\
\text { Thomson and Ryan }\end{array}$ & 2009 & $\begin{array}{l}\text { It was concluded that choice was influenced by } \\
\text { geographical accessibility, pregnancy complications, and } \\
\text { availability of alternative places of delivery. }\end{array}$ \\
\hline $\begin{array}{l}\text { An assessment of the cost-effectiveness of } \\
\text { midwife-led care in the United Kingdom. }\end{array}$ & Ryan, Revill, Devane and Normand & 2012 & $\begin{array}{l}\text { Expanding midwife-led maternity services for eligible } \\
\text { women may offer a means of reducing costs compared to } \\
\text { the current leading model of care. }\end{array}$ \\
\hline $\begin{array}{l}\text { Improving Quality and Safety in Maternity Care: } \\
\text { The Contribution of Midwife-Led Care [15] }\end{array}$ & $\begin{array}{l}\text { Sandall, Devane, Soltani, Hatem and } \\
\text { Gates }\end{array}$ & 2010 & $\begin{array}{l}\text { Fetal loss is reduced under } 24 \text { weeks' gestation in midwife- } \\
\text { led models of care, and ensuring that the effectiveness of } \\
\text { midwife-led models of care on mothers' and infants' health } \\
\text { and well-being are assessed in the longer postpartum } \\
\text { period. }\end{array}$ \\
\hline $\begin{array}{l}\text { Factors influencing women's choice of place of } \\
\text { delivery in rural Malawi-an explorative study } \\
\text { [31] }\end{array}$ & Seljeskog, Sundby and Chimango & 2006 & $\begin{array}{l}\text { Cultural aspects, such as, impact of decision makers on } \\
\text { women, perceptions of danger signs, and traditional views } \\
\text { about child birth were important to be addressed. }\end{array}$ \\
\hline $\begin{array}{l}\text { Factors affecting the midwifery led service } \\
\text { provider model in Pakistan [32] }\end{array}$ & Shahnaz & 2010 & $\begin{array}{l}\text { In midwifery led care women received timely services in } \\
\text { terms of maternity care during different phases of childbirth } \\
\text { by independent midwife practitioners and midwives } \\
\text { working in private sectors. }\end{array}$ \\
\hline $\begin{array}{l}\text { Antenatal, delivery and postnatal comparisons } \\
\text { of maternal satisfaction with two pilot Changing } \\
\text { Childbirth schemes compared with a traditional } \\
\text { model of care [33] }\end{array}$ & Spurgeon, Hicks and Barwell & 2001 & $\begin{array}{l}\text { The midwives acted as partners during the antenatal, } \\
\text { delivery and postnatal periods. }\end{array}$ \\
\hline $\begin{array}{l}\text { Care and environment in midwife-led and } \\
\text { obstetric-led units: a comparison of mothers' } \\
\text { and birth partners' perceptions [2] }\end{array}$ & Symon, Dugard, Butchart, Carr and Paul. & 2011 & $\begin{array}{l}\text { Relevant information to women helps them to make } \\
\text { informed choices related to care during child birth. }\end{array}$ \\
\hline $\begin{array}{l}\text { Intrapartum and postpartum care in Sweden: } \\
\text { women's opinions and risk factors for not being } \\
\text { satisfied }\end{array}$ & Waldenstrom, Rudman, and Hildingsson. & 2006 & $\begin{array}{l}\text { Midwives should work with women to enhance their } \\
\text { personal control by providing them client-centered } \\
\text { maternity care. }\end{array}$ \\
\hline $\begin{array}{l}\text { Team midwife care: maternal and infant } \\
\text { outcomes }\end{array}$ & $\begin{array}{l}\text { Waldenstrom, McLachlan, Forster, } \\
\text { Brennecke and Brown }\end{array}$ & 2001 & $\begin{array}{l}\text { Findings suggest that team midwifery as it is practiced is a } \\
\text { safe alternative for women. }\end{array}$ \\
\hline
\end{tabular}

Table 1: Brief overview of the studies included.

\section{Competent care providers}

Women consider competency as an important component of MLC that leads to client satisfaction. A midwife's competency means that she is knowledgeable and skilful to provide care and advice to women during the antenatal, intranatal, and postpartum periods. Moreover, the midwife is responsible for and competent to conduct vaginal deliveries and provide care to the newborn (ICM, 2005). Such competency can be achieved through continuous skills practice and continuous education of the midwives. Hence, midwives must follow the competency standards to provide safe and effective practice to women and their newborns, as stated in the midwifery curriculum (ICM, 2005).

Studies suggest that midwives should be competent because women consider them as their most appropriate primary health care providers for themselves and their newborns. In addition to this, women want midwives to be able to identify problems and refer them to specialists as needed $[7,18]$. Moreover, several other studies related to midwives competencies suggest that women who establish contact with midwives during the antenatal period are less likely to experience fetal loss before 24 weeks' gestation. Thus, competency is important in terms of birth outcomes $[1,5,16]$. 
Furthermore, maternal and neonatal outcomes, such as, spontaneous vaginal birth and early breastfeeding initiation are improved in MLC (Masterson) [9]. The use of less medical interventions during labor, such as, induction and augmentation of labor, episiotomy, instrumental deliveries, use of analgesia and anesthesia is minimized in MLC $[9,34,35]$.

A quantitative prospective cohort study was conducted by Johnson and Davis [36] to evaluate the safety of planned home birth for low risk women, conducted by certified professional midwives, in North America. The study concluded that home deliveries conducted by certified professional midwives were associated with low medical intervention rates and low intrapartum and neonatal mortality rates. As a result, women reported a high degree of safety and maternal satisfaction.

A study conducted by Shahnaz [32] identified the factors affecting the midwifery led service provider model in Pakistan. One of the findings of the study concluded that women received timely services in terms of maternity care during different phases of childbirth by independent midwife practitioners and midwives working in private sectors. Moreover, women with complicated obstetrical and medical conditions were provided basic maternity care and were referred to appropriate health care facilities immediately. As a result, women had a positive child birth experience.

\section{Cost of care in MLC}

Cost is one more important element for women receiving antenatal, intranatal, and postnatal care. The International Confederation of Midwives (ICM) believes that MLC is cost effective and sustainable, particularly in the high cost of health care worldwide fiscal situation (ICM Position Statement, 2011). Literature has revealed that MLC saves the cost of theatre, drugs, medical staffing, and other ongoing medical interventional costs, such as, epidural procedures [36]. Particular to staffing, studies contradict that major cost savings made by midwife-led units is questionable and is not well supported by evidence. As few studies suggest that women need one-to-one support during labor wherever they choose to give birth; so, staffing costs are not likely to differ between midwife led units and obstetric led units $[1,5,37]$.

Units that specialize in normal births, such as midwife-led units, can save money through decreased provision of epidural analgesia, nerve block, and increased used of non-pharmacological pain relief methods to enhance client satisfaction; they promote other analgesic and pain relief modalities for normal birth [26]. After an analysis of literature, the researcher found that very little is discussed about cost in MLC. Thus, more studies are suggested to explore the perceptions of women and the impact of cost to design alternative models of maternity care, such as MLC.

A systematic review of the literature was conducted by Ryan, Revill, Devane, and Normand [38], to analyze the existing evidences on the cost-effectiveness of midwife led care as compared with consultant led care. A total of twelve electronic databases were reviewed for relevant papers relating to the costs of midwife led models of care. The review concluded that for eligible women, expansion of midwife-led maternity services may help reduce costs, as compared to the consultant led care. Moreover, the study also suggested the need for further economic evaluations of models of maternity care in the United Kingdom.
Rasool [39] conducted a study to explore the experiences of community midwives, traditional birth attendants, and community people about the emerging role of community midwives in Baluchistan, Pakistan. As Pakistan offers a fee-for-service model, so, one of his study findings, related to the range of charges and the community's attitude regarding fees payment, revealed that women found the services provided by community midwives cost effective as compared to doctors. Whereas, a few women shared that the charges of services provided by community midwives were expensive as compared to the traditional birth attendants.

\section{Women's choice}

A woman's choice is also an important aspect of maternity care. Choice is defined as providing delivery options to women during childbirth about place for delivery, that is, home or facility based, and also providing choices about water birth. In addition, choices related to different positions during labor and pain relieving measures, apart from analgesia, are also provided by focusing on the philosophy of the natural birth process (ICM Position Statement). Relevant information and knowledge are prerequisites for women to make informed choices related to care during child birth $[33,40]$. The concept of choice is mostly described in terms of place of delivery and use of medical interventions, which mainly include the obstetric led model of care [40].

To explore women's varying experiences and a perception regarding choice in place of delivery, a descriptive comparative study was conducted. When different places of birth were compared, most of the women's decision focused on safety. Consultant-led care was associated with greater safety; whereas, MLC was associated with greater psycho-social support. It was concluded that choice was influenced by geographical accessibility, pregnancy complications, and availability of alternative places of delivery [41].

Moreover, the literature pertinent to women's choice during the intranatal period showed that they wanted appropriate and accurate information about the different phases of childbirth from the midwife.

Pitchforth, et al. [41] conducted a qualitative study to explore women's perceptions of "choice" of place of delivery in remote and rural areas in the north of Scotland where various maternity care models existed. The findings from the focus group discussions with women identified choice as one of the main themes. Moreover, it was found that choice was a multifaceted concept for women because choice could be inferred, experienced, and exercised in many ways. It was also highlighted that women are at times not given choices due to certain restricting factors, such as perceptions of women about quality and safety in home deliveries, and social, cultural, and financial influences. The findings of the study suggested that choice can play an important role in promoting MLC, conducting home births, and minimizing the medicalization of birth. In addition, the findings recommended that healthcare professionals can play a critical role in providing adequate information to women about choice by focusing on the personal, social, and cultural factors.

An explorative study was conducted by Seljeskog, Sundby, and Chimango [31] in the Mangochi area in Malawi. The purpose of the study was to investigate the individual, community, and health facility level factors influencing women's choice of delivery place. One of the study findings revealed that cultural aspects, such as, impact of decision makers on women, perceptions of danger signs, and traditional views about child birth were important components that 
needed to be addressed. Cultural needs need to be fulfilled to minimize anxiety, fear, and feeling of insecurity among women during the child birth process.

Moreover, women are empowered in midwifery led care to make choices, regarding their childbirth, with the help of the care provider (Gibbins and Thomson) [7]. A metasynthesis of six qualitative studies regarding midwifery care was done by Kennedy, Rousseau, and Low [32] to explore common themes and descriptions among the six studies for further exploration of the concept of midwifery care and for creating a framework for further metasynthesis of qualitative studies of midwifery practice in the USA. The collective analysis of the studies disclosed that a multifaceted and active interaction, about the relevant information, exists between the woman and the midwife in the maternity care cycle that empowers women to make choices.

\section{Women's Control during labor}

The other important element for women in MLC is 'control'. Control is defined as enhancing a client's confidence and ability to make her self-efficacious in giving birth and providing care for the baby in the environment where she delivers [5,7].

A correlational descriptive study by Goodman, Mackey, and Tavakoli [27] was conducted at two medical centres in the United States to examine the association of multiple factors with childbirth satisfaction. Questionnaires were completed by women $(n=60)$ aged between 18-46 years, and who had had spontaneous vaginal deliveries. Obstetrical data was collected from the medical record. Researchers used the labor agentry scale, the McGills pain questionnaire, and the Mackey childbirth satisfaction rating scale. The findings of the study revealed that women experienced high childbirth satisfaction and personal control during labor. Although, most of the women felt a moderate degree of pain but they were totally satisfied with the childbirth experience. The study also concluded that during childbirth personal control of the woman was a crucial factor that was related to the women's satisfaction with the childbirth experience. The study recommended that women's personal control should be facilitated during childbirth.

Another study by Christiaens and Bracke [42] was done to examine multiple determinants: the fulfillment of expectations, labor pain, personal control, and self-efficacy, for their association with satisfaction with childbirth in a cross-national perspective. Satisfaction with childbirth was measured by the Mackey childbirth satisfaction rating scale and labor pain was rated retrospectively using the Visual Analogue Scales. Personal control was assessed with the Wilma Delivery Expectancy/ Experience Questionnaire and the Pearlin and Scholar's mastery scale. After analysis, it was concluded that maternal satisfaction with childbirth was most consistently related to the fulfillment of expectations. The findings of this study also show that personal control of woman can work as a buffer to increase women's satisfaction related to child birth experiences. Hence, it is important to help women to enhance their personal control (self-efficacy) during child birth.

The findings of the above mentioned study also indicated a significant negative relationship between maternal anxiety and feelings of control during labor. It was suggested that midwives should work with women to enhance their personal control by providing them client-centered maternity care in which they are able to take decisions and formulate their birth plan. Similar findings were shared by other researchers $[1,19,30,42]$.

\section{Conclusion}

In summary, this literature review briefly discussed women's experiences related to MLC. The review highlighted the significance of women satisfaction in MLC, and viewing MLC as women-centred and cost-effective service provision.

\section{Acknowledgement}

The author gives special thanks to the Supervisor, Committee members, and faculty members at the Aga Khan University School of Nursing and Midwifery for their continuous cooperation.

\section{References}

1. International Confederation of Midwives (2011) Position Statement. Appropriate maternity services for normal pregnancy, childbirth and the postnatal period.

2. Symon AG, Dugard P, Butchart M, Carr V, Paul J (2011) Care and environment in midwife-led and obstetric-led units: a comparison of mothers' and birth partners' perceptions. Midwifery 27: 880-886.

3. Cheung NF, Mander R, Wang X, Fu W, Zhou H, et al. (2011) Views of Chinese women and health professionals about midwife-led care in China. Midwifery 27: 842-847.

4. Doherty ME (2010) Midwifery care: reflections of midwifery clients. J Perinat Educ 19: 41-51.

5. Begley C, Devane D, Clarke M (2009) The report of the MidU study School of Nursing and Midwifery, Trinity College Dublin, Women's Evaluations of Maternity Care, The MidU Survey.

6. Hildingsson I, Thomas JE (2007) Women's perspectives on maternity services in Sweden: processes, problems, and solutions. J Midwifery Womens Health 52: 126-133.

7. Gibbins J, Thomson AM (2001) Women's expectations and experiences of childbirth. Midwifery 17: 302-313.

8. Dencker A, Taft C, Bergqvist L, Lilja H, Berg M (2010) Childbirth experience questionnaire (CEQ): development and evaluation of a multidimensional instrument. BMC Pregnancy Childbirth 10: 81.

9. Masterson A (2010) Core and developing role of the midwife: Literature review. Final Report 2010. AMC Literature Review Core and Developing Role of the Midwife Midwifery 2020 1-16.

10. Biró MA, Waldenström U, Brown S, Pannifex JH (2003) Satisfaction with team midwifery care for low- and high-risk women: a randomized controlled trial. Birth 30: 1-10.

11. Waldenström U, Rudman A, Hildingsson I (2006) Intrapartum and postpartum care in Sweden: women's opinions and risk factors for not being satisfied. Acta Obstet Gynecol Scand 85: 551-560.

12. Australian College of Midwives (2007) Midwifery continuity of care.

13. Green JM, Renfrew MJ, Curtis PA (2000) Continuity of carer: what matters to women? A review of the evidence. Midwifery 16: 186-196.

14. Waldenstrom U, McLachlan H, Forster D, Brennecke S, Brown S (2001) Team midwife care: maternal and infant outcomes. Australian and New Zealand Journal of Obstetrics and Gynecology 41: 257-264.

15. Sandall J, Devane D, Soltani H, Hatem M, Gates S (2010) Improving quality and safety in maternity care: the contribution of midwife-led care. J Midwifery Womens Health 55: 255-261.

16. Mohajer M, Hughes A, Ghosh S, (2009) Midwifery-led birthing units. Obstetrics, Gynecology and Reproductive Medicine 19: 169-171.

17. Hutton EK, Reitsma AH, Kaufman K (2009) Outcomes associated with planned home and planned hospital births in low-risk women attended by midwives in Ontario, Canada, 2003-2006: a retrospective cohort study. Birth 36: 180-189.

18. Downe T (2008) Normal childbirth: Evidence and debate (2nd ed.). Churchill Livingstone, Edinburgh. 
Citation: Shahid S, Jan R, Qureshi RN, Rattani S (2014) A Review Related to Midwifery Led Model of Care. J Gen Practice 2: 180. doi:

19. Hodnett ED, Gates S, Hofmeyr GJ, Sakala C (2007) Continuous support for women during childbirth. Cochrane Database Syst Rev: CD003766.

20. Wilkins R (2000) Poor relations: The paucity of the professional paradigm in the midwife- mother relationship. London: Macmillan Press.

21. Parratt J, Fahy K (2004) Creating a 'safe' place for birth: An empirically grounded theory. New Zealand College of Midwives Journal 30: 11-14.

22. Kennedy HP, Shannon MT, Chuahorm U, Kravetz MK (2004) The landscape of caring for women: a narrative study of midwifery practice. J Midwifery Womens Health 49: 14-23.

23. Rooks JP (1997) Midwifery and childbirth in America. Philadelphia: Temple University Press.

24. James S (1997) With woman: The nature of the midwifery relation. $\mathrm{PhD}$ University of Alberta.

25. Doherty ME (2010) Midwifery care: reflections of midwifery clients. J Perinat Educ 19: 41-51.

26. Eide B, Nilsen AB, Rasmussen S (2009) Births in two different delivery units in the same clinic--a prospective study of healthy primiparous women. BMC Pregnancy Childbirth 9: 25.

27. Goodman P, Mackey MC, Tavakoli AS (2004) Factors related to childbirth satisfaction. J Adv Nurs 46: 212-219.

28. Hutton EK, Reitsma AH, Kaufman K (2009) Outcomes associated with planned home and planned hospital births in low-risk women attended by midwives in Ontario, Canada, 2003-2006: a retrospective cohort study. Birth 36: 180-189.

29. Kennedy HP, Rousseau AL, Low LK (2003) An exploratory metasynthesis of midwifery practice in the United States. Midwifery 19: 203-214.

30. Larkin P, Begley CM, Devane D (2009) Women's experiences of labour and birth: an evolutionary concept analysis. Midwifery 25: 49-59.

31. Seljeskog L, Sundby J, Chimango J (2006) Factors influencing women's choice of place of delivery in rural Malawi--an explorative study. Afr J Reprod Health 10: 66-75.
32. Shahnaz S (2010) Factors affecting the midwifery led service provider model in Pakistan. Unpublished Master thesis, Aga Khan University, Pakistan.

33. Spurgeon P, Hicks C, Barwell F (2001) Antenatal, delivery and postnatal comparisons of maternal satisfaction with two pilot Changing Childbirth schemes compared with a traditional model of care. Midwifery 17: 123-132.

34. Downe T (2008) Normal childbirth: Evidence and debate (2nd ed.). Churchill Livingstone, Edinburgh.

35. Winterton Report (1992) Health committee report on the maternity services. Volume 1 ,London: HMSO.

36. Department of Health (2007) Maternity Matters: Choice, access and continuity of care in a safe service.

37. Allen I, Dowling S, Williams S (1997) A leading role for midwives? Policy Studies Institute, London 832.

38. Ryan P, Revill P, Devane D, Normand C (2013) An assessment of the cost-effectiveness of midwife-led care in the United Kingdom. Midwifery 29: 368-376.

39. Rasool G (2010). Emerging role of community based midwife (CMW) in Pakistan: A case of district Lasbela, Balochistan province. Unpublished Master thesis, Aga Khan University, Pakistan.

40. Hindley C, Thomson AM (2005) The rhetoric of informed choice: perspectives from midwives on intrapartum fetal heart rate monitoring. Health Expect 8: 306-314.

41. Pitchforth E, van Teijlingen E, Watson V, Tucker J, Kiger A, et al. (2009) "Choice" and place of delivery: a qualitative study of women in remote and rural Scotland. Qual Saf Health Care 18: 42-48.

42. Christiaens W, Bracke P (2007) Assessment of social psychological determinants of satisfaction with childbirth in a cross-national perspective. BMC Pregnancy Childbirth 7: 26. 